\title{
Has "The Outline of the Plan for the Reform and Development of the Pearl River Delta" Promoted to the Coordination of Guangdong-Hong Kong-Macao Greater Bay Area
}

\author{
Sixin Zheng \\ School of Economics, Jinan University, Guangzhou, China \\ Email: senn_47@163.com
}

How to cite this paper: Zheng, S.X. (2019) Has "The Outline of the Plan for the Reform and Development of the Pearl River Delta" Promoted to the Coordination of Guangdong-Hong Kong-Macao Greater Bay Area. Modern Economy, 10, 1348-1367. https://doi.org/10.4236/me.2019.104091

Received: March 27, 2019

Accepted: April 22, 2019

Published: April 25, 2019

Copyright ( 2019 by author(s) and Scientific Research Publishing Inc. This work is licensed under the Creative Commons Attribution International License (CC BY 4.0).

http://creativecommons.org/licenses/by/4.0/

(c) (i) Open Access

\begin{abstract}
The construction of the Guangdong-Hong Kong-Macao Greater Bay Area is an important regional development strategy implemented by our country in the new era. The development of coordination is the point. It is known that the scope of implementation of the outline includes the Pearl River Delta region and Hong Kong and Macao, consistent with the scope of Guangdong-Hong Kong-Macao Greater Bay Area. So, as to whether this outline has promoted the coordinated development of Greater Bay Area, this paper, based on the counterfactual analysis, constructs the HCW model and makes an empirical analysis from three aspects, regional economic relations, regional economic growth and regional economic differences. The results show that the outline did strengthen relations of Great Bay area, promote the regional economic growth and also have a positive effect on the reduction of regional economic differences. These conclusions can provide valuable reference for promoting the coordination of Guangdong-Hong Kong-Macao Greater Bay Area.
\end{abstract}

\section{Keywords}

Guangdong-Hong Kong-Macao Greater Bay Area, Pearl River Delta, The Coordination of Regional Development, Counterfactual Analysis

\section{Introduction}

In 2017, the Government Work Report of China has proposed "to formulate a 
development plan of Guangdong-Hong Kong-Macao Great Bay Area”, which means that the construction of Guangdong-Hong Kong-Macao Great Bay Area has entered a new era of China's regional development sequence of national strategy. Due to the Great Bay Area including Guangdong, Hong Kong and Macao, which are three separate customs territories (Guangdong pearl river delta region belonging to the mainland customs territory), involving in nine cities in the pearl river delta in Guangdong, Hong Kong and Macao, a total of 11 cities, how to promote the coordinated development is the major issue facing the construction of the Great Bay Area and also an important tasks to complete in the process of implement the development plan for the Great Bay Area. In this respect, the implementation of Outline Development Plan for the Pearl River Delta Region (2008-2020) (hereinafter referred to as the outline) undoubtedly provides valuable practical experience.

The Outline was officially issued and implemented by the National Development and Reform Commission after the approval of the State Council in December 2008. It is an important plan on how to develop scientifically in the Pearl River Delta region at the national strategic level during the critical period of the transformation of economic structure and the change of development mode. Its core lies in promoting the transformation of economic development and regional coordinated development in the Pearl River Delta region, Hong Kong and Macao [1]. The main target areas of the Outline are the Pearl River Delta of Guangdong Province, including Guangzhou, Shenzhen, Zhuhai, Foshan, Huizhou, Dongguan, Zhongshan, Jiangmen and Zhaoqing. At the same time, the two special administrative regions of Hong Kong and Macao will be included in the planning in terms of development orientation and regional cooperation. It can be seen that the implementation scope of the Outline covers the Pearl River Delta, Hong Kong and Macao, which is completely consistent with the current geographical scope of the Great Bay Area. Therefore, in this paper, we will transform the "equivalent" of the Pearl River Delta area covered by the Outline into the Great Bay Area of Guangdong, Hong Kong and Macao in order to be consistent with the concept of the Great Bay Area currently proposed.

We believe that the experience of the Outline in promoting regional coordinated development is worth learning in planning and promoting the coordinated development of Great Bay Area. So, does the implementation of the Outline promote the coordinated development of Great Bay Area as planned? This is a problem that needs to be analyzed and evaluated scientifically.

\section{Related Literature}

Actually, about the effects of the outline, it has attracted the attention of many scholars. In the early stages of the outline, most of scholar study on it with qualitative analysis. For example, Yao Huasong and Xu Xueqiang, When interpreting policies, think that the new idea of the coordination of regional development is not fully integrated, which on the one hand, to promote the pearl river delta 
region in the areas of infrastructure, transportation, health care, social security, education and other public service facilities, on the other hand to keep local autonomy development, keep the local characteristic industry, local technology, the development of local cultural, protect the diversity of the local economy and society [2]. Ma Lindong, Xu Qiu believe that the key of regional economic cooperation of the Pearl River Delta is the degree of differences and complementary between the industry after the analysis of the outline from three different level-the international level, domestic level and the regional level. With the continued implementation of the outline, some scholars began to estimating the impact of the outline with method of quantitative analysis [3]. Peng Xijun made a quantitative evaluation of the process of industrial integration in the Pearl River Delta since the implementation of the outline by calculating the industrial isomorphism coefficient, regional specialization and location quotient. The results show that the degree of inter-regional engineering is rising, and the industrial layout is evolving towards specialization and differentiation [4]. In addition, Guo Fang and Song Yu made a quantitative analysis of the effectiveness of local government policy innovation since the implementation of the Outline, pointing out that local governments have achieved remarkable results in institutional policy, instrumental policy and objective policy innovation [5]. From the existing research literature, no literature has been found to evaluate the implementation effect of the Outline from the perspective of regional coordinated development.

As we all know, the evaluation of regional development strategy, planning and policy implementation is an urgent research work. However, the research in this area depends on the progress of methods. In recent years, most economists carry out policy evaluation based on the counterfactual framework [6] developed by Rubin. That is to say, man-made control groups, which do not exist in fact, are used as counter facts, to reflect the causal relationship between things through the difference between counterfactual and factual, so as to evaluate the policy effect. The common methods of constructing counterfactual frameworks include breakpoint regression (RD), double difference (DID) and propensity matching score estimation (PSM). The application of these methods is based on strict preconditions and assumptions. Among them, RD requires the same individual characteristics near the breakpoint [7]. This method is mostly applied in the field of labor and education economics. Among them, RD requires the same individual characteristics near the breakpoint. This method is mostly applied in the field of labor and education economics. DID has been developed by Card and Krueger and applied in empirical research [8]. This method needs to satisfy the premise of randomness, that is, the selection of treatment group and control group must be random and affected by common factors, and the degree of influence must be the same [9]. PSM needs to satisfy the strong premise hypothesis of "strong negligibility hypothesis" [10]. In addition to the above assumptions, the application of these methods requires a large amount of sample data. As far as the theme of this study is concerned, the impact path of policy implementation on economic linkages and development in the Great Bay Area is complex 
and diverse. Moreover, for different regions in the Great Bay Area, the impact degree is also different. In addition, the cities covered by the outline are not random decisions made by policymakers, and the data time series of implementation is also relatively short. Therefore, if we use the above counter-factual analysis methods to evaluate the effect of regional coordinated development of policies, it will have inevitable limitations.

Through reviewing the relevant literature, we find that the counterfactual analysis method developed by Hsiao et al. [11]. can effectively solve the problems of strong premise assumptions and insufficient time series data faced by methods above. Hsiao et al. believe that the economic development of individuals in cross-section can be driven by common factors. Although these factors have different effects on each individual, due to the correlation between individuals in cross-section, the "counterfactual situation" of individuals in non-treatment group can be predicted by the relevant data known after the implementation of the policy. Ching et al. and Ke et al. successively used this method to identify the effect of CEPA on Hong Kong's service trade industry [12] and the impact of high-speed rail on the local economy [13]. They overcome the problems of missing variables and insufficient data in identifying and processing effects, and the results are robust. Therefore, this paper decides to use this method to evaluate whether the implementation of the Outline has promoted the coordinated development of Great Bay Area.

The rest of the paper is organized as follows: Section 2 discusses the counterfactual analysis method of regional coordinated development. It mainly constructs HCW model. Then, based on the data of cities in Great Bay Area from 1997 to 2015, the paper makes an empirical analysis of the coordinated development of Great Bay Area before and after the implementation of the Outline. Section 3, based on the results of empirical analysis, analyses whether the implementation of the Outline has promoted the coordinated development of Great Bay Area and the specific effect. Section 4 summarizes the analysis conclusion of this paper and puts forward the planning and policy suggestions for the coordinated development of the Great Bay Area.

\section{The Model and Estimation}

\subsection{Counterfactual Analysis Method}

In this section, according to the panel data evaluation method of Hsiao et al., we briefly introduce the counter-factual analysis ideas used to analyze the effect of regional coordinated development in the implementation of the Outline. Let $y_{i t}^{1}$

and $y_{i t}^{0}$ represent the coordinated development indicators of region $i$ in $t$ year respectively, and superscripts 1 and 0 indicate the implementation and non-implementation of the Outline respectively. Let $d_{i t}$ be the variable of policy intervention. When the Outline is implemented, the value is 1; on the contrary, the value is 0 . If the year of promulgation of the Pearl River Delta Planning Outline is $T_{1}$, the implementation effect of the Outline can be expressed as follows: 


$$
\Delta_{i t}=y_{i t}^{1}-y_{i t}^{0}, t>T_{1}
$$

However, we do not simultaneously observe $y_{i t}^{1}$ and $y_{i t}^{0}$. What can be observed in reality can be expressed as:

$$
y_{i t}=d_{i t} y_{i t}^{1}-\left(1-d_{i t}\right) y_{i t}^{0}
$$

where $d_{i t}=1$ if the city $i$ receives the Outline treatment and $d_{i t}=0$ otherwise.

From the above, we can see that the key to identify $\Delta_{i t}$ is to construct counterfacts $y_{i t}^{0}\left(i=1, \cdots, m, t>T_{1}\right)$. Referring to the method of Hsiao et al., the factors affecting the indicators of regional coordinated development can be divided into two parts. Part of the factor is the influence of $K$ common factors (unobservable) which change with time. It is expressed by factor vector $f_{t}$ of order $K \times 1$. These common factors can be the change of national macro-policy, the impact of domestic and foreign economic environment, technological progress and so on. Another factor is the random term $\alpha_{t}+u_{i t}$, where $\alpha_{t}$ is the individual fixed effect of the region, $u_{i t}$ is the random error of the region with $E\left(u_{i t}\right)=0$ and $\operatorname{cov}\left(u_{i t}, u_{j t}\right)=0, i \neq j$. Therefore, for all regions, $y_{i t}^{0}$ can be expressed as:

$$
y_{i t}^{0}=b_{i} f_{t}+\alpha_{t}+u_{i t}
$$

where, $b_{i}$ denotes the influence coefficient of common factors on each region, which can vary from region to region with $b_{i} \neq b_{j}$; and random error $u_{i t}$ is independent of policy intervention variable $d_{i t}$ condition with $E\left(u_{i t} \mid d_{i t}\right)=0$ ( $i=1, \cdots, m, j=m+1, \cdots, N)$.

From Equation (3), we can see that the correlation of the individual on the cross section comes from these unobservable common factors $f_{t}$ :

$$
\operatorname{cov}\left(y_{i t}, y_{j t}\right)=b_{i}^{\prime} E\left(f_{t} f_{t}^{\prime}\right) b_{j}
$$

Therefore, the time series data $y_{j t}^{0}$ of the control group before the implementation of the Outline can be used to fit the $y_{i t}^{0}$ of the treatment group, which can be expressed as:

$$
y_{i t}^{0}=E\left(y_{i t}^{0} \mid y_{j t}^{0}\right)+\varepsilon_{i t}=\alpha_{i}+\alpha_{i j}^{*} y_{j t}^{0}+u_{i t}^{*}
$$

By estimating coefficients $\alpha_{i}$ and $\alpha_{i j}^{*}$ and using the time series data $y_{j t}=y_{j t}^{0}\left(t>T_{1}\right)$ of the control group after the implementation of the Outline, the estimated value of counterfactual $\left.y_{i t}=y_{i t}^{0}\left(t>T_{1}\right)\right)$ can be obtained:

$$
\hat{y}_{i t}^{0}=\hat{\alpha}_{i}+\hat{\alpha}_{i j}^{*} y_{j t}^{0}
$$

Then, the net effect of the Outline on the region $i$ covered is as follows:

$$
\hat{\Delta}_{i t}=y_{i t}^{1}-\hat{y}_{i t}^{0}, t>T_{1}
$$

If $\Delta_{i t}$ is stable, the average treatment effect (ATE) is as follows:

$$
\hat{\Delta}_{i}=1 /\left(T-T_{1}\right) \sum_{t=T_{1}+1}^{T} \hat{\Delta}_{i t}
$$

where, Trepresents the end year of the evaluation of the policy effect of the Outline.

In order to minimize the prediction error, this paper uses methods of Hsiao et 
al. to construct the optimal control group [14]. That is, based on the adjusted $R$-square and Akaike Information Criterion (AICC), the best fitting $k(1 \leq k \leq n)$ regions were selected from $n$ control groups to estimate the value $\hat{y}_{i t}^{0}$ of counterfactual cases.

\subsection{Data and Settings}

As mentioned earlier, the main areas of implementation of the Outline are 9 cities in the Pearl River Delta region of Guangdong Province, but at the same time, in the Outline, the regional links and cooperation between the Pearl River Delta region and Hong Kong and Macao are emphasized. Therefore, the Pearl River Delta region and Guangdong-Hong Kong-Macao Great Bay Area are treated as two treatment groups when evaluating the impact of the Outline on the regional coordinated development. Based on the hypothesis of Hsiao et al. that individuals on the cross-section are driven by common factors, and considering minimizing the influence of regional heterogeneity, such as culture, climate and geography, this paper selected 9 other cities in Guangdong Province as the control group of the Pearl River Delta cities, namely Chaozhou, Jieyang, Maoming, Qingyuan, Shantou, Shanwei, Shaoguan, Yangjiang and Zhanjiang.

Regarding the selection of the control group between Hong Kong and Macao, this paper considers that although Hong Kong and Macao and the Mainland implement "one country, two systems", their economic development with the mainland is becoming closer and closer, and they have "common factors" of economic development. At the same time, considering that Hong Kong and Macao are the two windows through which the mainland of China connects with the world economic system, they are open to the outside world and have closer economic ties with the outside world, Therefore, the macro-environment and international environment of its economic operation also have the "common factors" needed to construct the control group. In order to select the best control group, this paper chooses 10 provinces and cities along the coast of China and 9 countries in Asia, Europe and the Americas to compare their GDP data with those of Hong Kong and Macao in the past 20 years, respectively. See Figure 1 and Figure 2.

As can be seen from the above Figure 1 and Figure 2, the development trend of Hong Kong and Macao is closer to that of the selected foreign economies. Therefore, this paper holds that the economic operation of Hong Kong and Macao is more influenced by the international macroeconomic environment. Compared with domestic provinces and cities, Hong Kong and Macao have more "common factors" with foreign economies. Based on the hypothesis of Hsiao et al. that individuals on the cross section are driven by common factors, this paper selects 9 foreign economies from Asia, Europe and America as the control group of Hong Kong and Macao.

As for the scope of the study, considering the promulgation of the Outline in December 2008, we regard 2009 as the first year of the implementation of the 


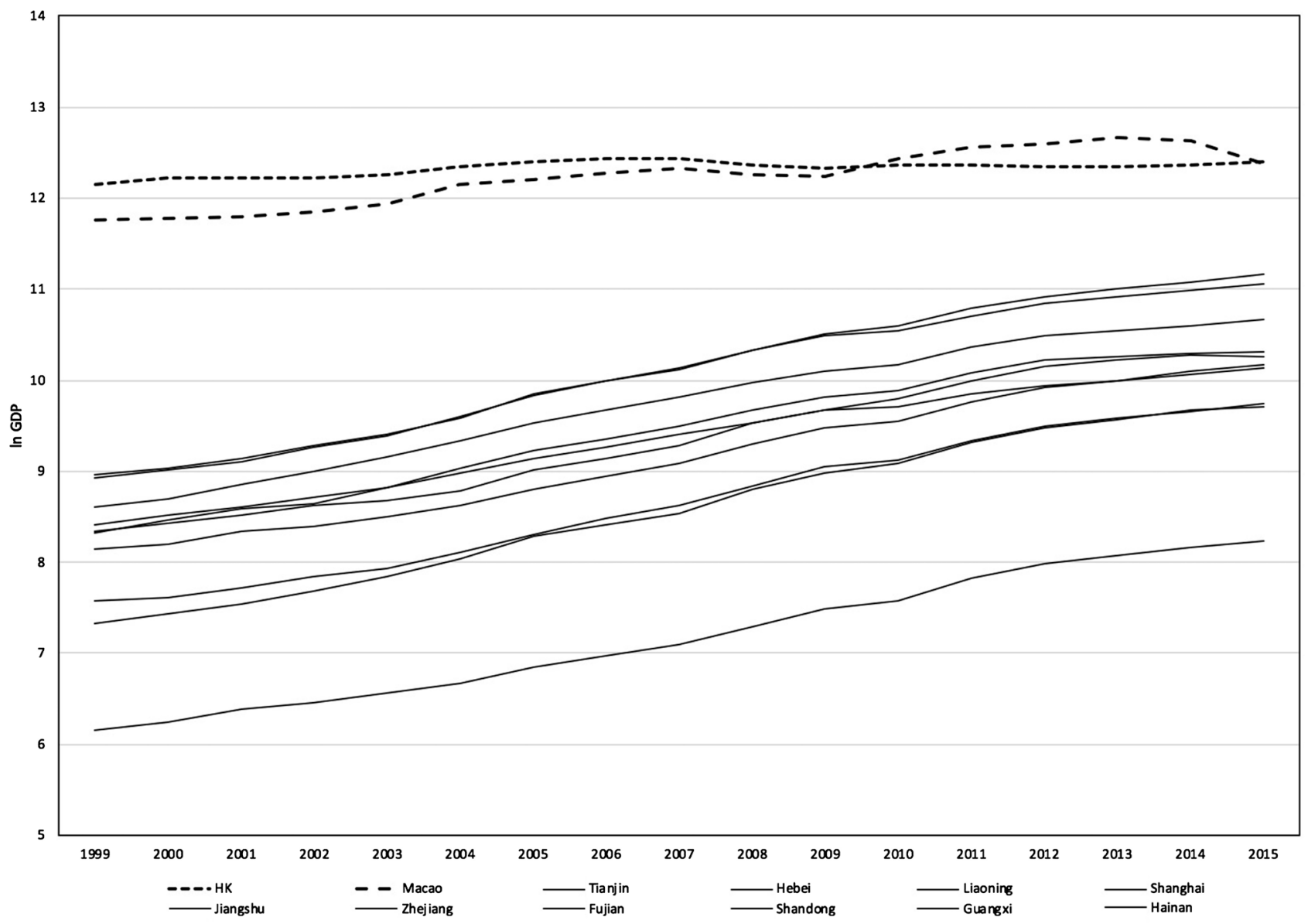

Figure 1. Comparison of economic development trends between Hong Kong and Macao and domestic economies.

Outline, and the period from 2009 to 2015 as the period of the implementation of the Outline. We select the 10-year data from 1999 to 2008 as the sample before the Outline treatment. In terms of data, the data of the cities in the Pearl River Delta are from the statistical information websites of the cities. The data of Hong Kong, Macao and the nine countries mentioned above are from the Federal Reserve Economic Online Data Database (FRED).

As mentioned above, this paper attempts to evaluate the regional coordinated development effect of the implementation of the Outline in the Guangdong-Hong Kong-Macao Great Bay Area. However, according to the existing literature, there is no unified criterion and evaluation method for regional coordinated development in academia at present. Most scholars evaluate regional economic coordinated development from one or several aspects, such as the degree of regional economic integration, regional division of labor, the degree of regional economic development gap or the speed of regional economic development [15] [16] [17]. Based on the concept of regional coordinated development defined by Qin Chenlin et al., which is "the coordinated development of regional economy refers to the process in which the economic links between regions become closer and closer, the economic interdependence deepens, the interrelated interaction and positive promotion of economic development, the 


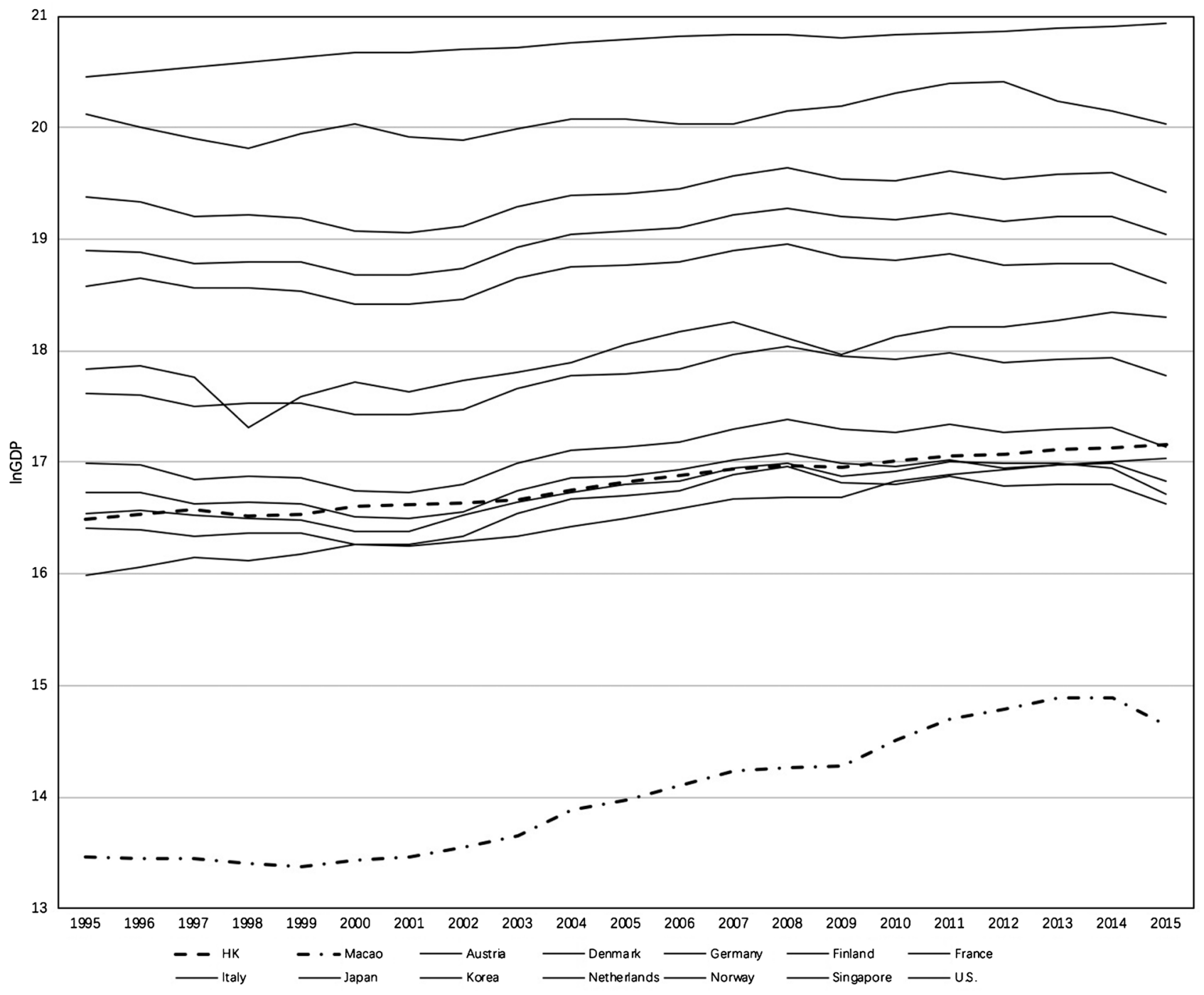

Figure 2. Comparison of economic development trends between Hong Kong and Macao and foreign economies.

sustainable development of the economies of all regions and the regional economic disparities tend to narrow under the conditions of regional opening up" [18], this paper measures regional coordinated development from three levels: regional economic links, regional economic growth and regional economic disparities.

Firstly, the gravitational model of spatial interaction is used to measure regional economic linkages. In the Pearl River Delta region, the successive development of highway, high-speed rail and urban rail makes the transportation convenience between cities continuously improve. Therefore, the traditional method of using spatial distance between two places in gravity model has been greatly limited. Considering that the modern transportation network is an important support for regional economic exchanges and cooperation, this paper uses the shortest distance between regions to correct the spatial distance in the traditional gravity model based on the high-speed road network and rail transit network. The specific formulas for calculating the degree of economic linkages 
among cities are as follows:

$$
d_{i j}=\left(\sqrt{P_{i} G D P_{i}} \times \sqrt{P_{j} G D P_{j}}\right) / T_{i j}^{2}
$$

where, $P_{i}$ and $P_{j}$ denote the total population of region $i$ and region $j$ at the end of the year; $G D P_{i}, G D P_{j}$ denote the Gross Regional Product of region $i$ and region $j$, and $T_{i j}$ denotes the shortest distance between region $i$ and region $j$. By inquiring the opening time of expressways and rail transit in the Pearl River Delta region, ArcGIS 9.2 software was used to establish the database of urban node elements in the Pearl River Delta from 2008 to 2015, and eight $9 * 9$ timedistance matrices were obtained by network analysis function. The regional economic linkages in the Pearl River Delta region are calculated by the following formula:

$$
D_{t}=\sum_{j=1}^{m-1} \sum_{i=1}^{m-1} d_{i j} /(m-1)^{2}
$$

The coordinated development of a regional economic entity requires the participation of all regions within it. One of the purposes of regional coordinated development is to promote the sustainable development of the economy of all regions. If the economy of each region in the region can be sustained development, it means that there is a positive role in promoting economic development among them, but also means that the overall efficiency of economic development of the region's economy is constantly improving. Therefore, in order to better observe the economic development situation of each region in Guangdong, Hong Kong, Macao, this paper uses coefficient of variation to describe the economic growth status of each region, which is recorded as $\mathrm{CV}$ :

$$
C V_{t}=\frac{\sqrt{\sum\left(y_{i}-\bar{y}\right)^{2} / n}}{\bar{y}}
$$

where, $C V_{t}$ represents the coefficient of variation of GDP growth rate among $n$ cities in region in $t$ Year, $y_{i}$ represents the GDP growth rate of city $i$, and $\bar{y}$ represents the average growth rate of $n$ cities in the region. The larger the coefficient of variation is, the greater the relative difference of regional economic growth is, and the smaller the positive promoting effect of economic growth among regions is. On the contrary, the same is true.

For the measurement of regional economic disparity, the most widely used and mature methods are standard deviation, Gini coefficient, Theil index and so on. Because Theil index can divide the total differences into inter-regional and intra-regional differences, it can better reflect regional economic differences. In this paper, the Theil index is calculated by weighting the proportion of population and expressed by $T$.

$$
T=\sum\left(\frac{Y_{i}}{Y} \times \log \left(\left(\frac{Y_{i}}{Y}\right) /\left(\frac{P_{i}}{P}\right)\right)\right)
$$

where, $Y_{i}$ is the GDP of city $i, Y$ is the total GDP of self-determination; $P_{i}$ is the population of city $i, P$ is the total population of the region. The size of the 
Theil index reflects the size of regional economic disparity. The smaller the Theil index is, the smaller the regional economic disparity is.

As can be seen from Table 1 and Table 2, the fitting effect of control group Table 1. Screening results of optimal control group (GDP).

\begin{tabular}{|c|c|c|c|c|}
\hline Treatment & Control & Coefficient & Std. Err. & R-square \\
\hline \multirow{3}{*}{ Hong Kong } & Singapore & $1.033^{* * *}$ & 0.105 & \multirow{3}{*}{0.9937} \\
\hline & Italy & 0.017 & 0.049 & \\
\hline & U.S.A & $-0.557^{\star * *}$ & 0.163 & \\
\hline \multirow{4}{*}{ Macao } & Singapore & $2.039^{* * *}$ & 0.221 & \multirow{4}{*}{0.9974} \\
\hline & Italy & $2.967^{\star * *}$ & 0.463 & \\
\hline & The Republic of Korea & $-0.202^{* *}$ & 0.075 & \\
\hline & Netherlands & $-2.555^{\star * *}$ & 0.511 & \\
\hline \multirow{4}{*}{ Guangzhou } & Jieyang & $-0.480^{\star * \star}$ & 0.096 & \multirow{4}{*}{0.9992} \\
\hline & Chaozhou & $0.872^{\star * *}$ & 0.204 & \\
\hline & Qingyuan & $-0.441^{\star * *}$ & 0.061 & \\
\hline & Shaoguang & $1.399^{* * *}$ & 0.142 & \\
\hline \multirow{4}{*}{ Shenzhen } & Jieyang & $-0.839^{\star * \star}$ & 0.141 & \multirow{4}{*}{0.9986} \\
\hline & Chaozhou & $1.378^{\star * *}$ & 0.299 & \\
\hline & Qingyuan & $-0.789^{\star * *}$ & 0.090 & \\
\hline & Shaoguang & $1.829^{* * *}$ & 0.208 & \\
\hline \multirow{2}{*}{ Zhuhai } & Qingyuan & $-0.403^{\star * \star}$ & 0.074 & \multirow{2}{*}{0.9979} \\
\hline & Shaoguang & $1.642^{* * *}$ & 0.097 & \\
\hline \multirow{3}{*}{ Foshan } & Jieyang & $-0.214^{\star * *}$ & 0.057 & \multirow{3}{*}{0.9996} \\
\hline & Shaoguang & $1.051^{\star * *}$ & 0.078 & \\
\hline & Zhanjiang & $0.483^{* * *}$ & 0.092 & \\
\hline \multirow{2}{*}{ Huizhou } & Yangjiang & $0.733^{* * *}$ & 0.085 & \multirow{2}{*}{0.9992} \\
\hline & Shanwei & $0.312^{* * *}$ & 0.093 & \\
\hline \multirow{3}{*}{ Dongguang } & Jieyang & $-1.320^{\star * *}$ & 0.137 & \multirow{3}{*}{0.9979} \\
\hline & Shaoguang & $0.821^{* * *}$ & 0.218 & \\
\hline & Shanwei & $1.714^{* * *}$ & 0.241 & \\
\hline \multirow{3}{*}{ Zhongshan } & Jieyang & $-0.919^{\star * *}$ & 0.162 & \multirow{3}{*}{0.998} \\
\hline & Chaozhou & $1.017^{\star *}$ & 0.378 & \\
\hline & Shaoguang & $1.229^{* * *}$ & 0.246 & \\
\hline \multirow{2}{*}{ Jiangmen } & Qingyuan & $0.388^{\star * *}$ & 0.023 & \multirow{2}{*}{0.9993} \\
\hline & Shanwei & $0.353^{* * *}$ & 0.031 & \\
\hline \multirow{5}{*}{ Zhaoqing } & Jieyang & $0.499^{* * *}$ & 0.038 & \multirow{5}{*}{0.9998} \\
\hline & Chaozhou & $1.007^{\star * *}$ & 0.125 & \\
\hline & Zhanjiang & $-0.934^{\star * *}$ & 0.095 & \\
\hline & Yangjiang & $1.701^{\star * *}$ & 0.109 & \\
\hline & Shanwei & $-1.100^{\star * *}$ & 0.081 & \\
\hline
\end{tabular}

Note: ${ }^{* *},{ }^{* *},{ }^{*}$ respectively represent that the estimated coefficients pass the significance level test of $1 \%$, $5 \%$ and $10 \%$. 
Table 2. Screening results of optimal control group (per capita GD).

\begin{tabular}{|c|c|c|c|c|}
\hline Treatment & Control & Coefficient & Std. Err. & R-square \\
\hline Hong Kong & Singapore & $0.986^{\star * *}$ & 0.060 & 0.9637 \\
\hline \multirow{2}{*}{ Macao } & Singapore & $1.035^{\star * *}$ & 0.162 & \multirow{2}{*}{0.9844} \\
\hline & Germany & $0.646^{\star * *}$ & 0.117 & \\
\hline \multirow{2}{*}{ Guangzhou } & Jieyang & $-0.700^{\star * *}$ & 0.161 & \multirow{2}{*}{0.9921} \\
\hline & Yangjiang & $1.523^{* * *}$ & 0.093 & \\
\hline \multirow{2}{*}{ Shenzhen } & Jieyang & $-0.627^{* * *}$ & 0.156 & \multirow{2}{*}{0.9902} \\
\hline & Yangjiang & $1.322^{* * *}$ & 0.089 & \\
\hline \multirow{3}{*}{ Zhuhai } & Shanwei & $-0.526^{* * *}$ & 0.118 & \multirow{3}{*}{0.9983} \\
\hline & Shaoguang & $0.933^{* * *}$ & 0.121 & \\
\hline & Chaozhou & $0.462^{\star \star \star}$ & 0.136 & \\
\hline \multirow{4}{*}{ Foshan } & Yangjiang & $0.914^{* * *}$ & 0.259 & \multirow{4}{*}{0.9995} \\
\hline & Shanwei & $-1.279^{\star * *}$ & 0.098 & \\
\hline & Shaoguang & $0.692^{\star *}$ & 0.228 & \\
\hline & Chaozhou & $0.788^{\star * *}$ & 0.150 & \\
\hline \multirow{2}{*}{ Huizhou } & Shaoguan & $0.470^{\star * *}$ & 0.078 & \multirow{2}{*}{0.9983} \\
\hline & Maoming & $0.408^{* * *}$ & 0.087 & \\
\hline \multirow{4}{*}{ Dongguan } & Shanwei & $-1.488^{\star * *}$ & 0.273 & \multirow{4}{*}{0.9963} \\
\hline & Shaoguang & $2.413^{* * *}$ & 0.330 & \\
\hline & Maoming & $1.167^{* * *}$ & 0.240 & \\
\hline & Qingyuan & $-0.746^{* * *}$ & 0.134 & \\
\hline \multirow{2}{*}{ Zhongshan } & Jieyang & $-1.019^{\star * *}$ & 0.182 & \multirow{2}{*}{0.9937} \\
\hline & Zhanjiang & $2.117^{\star * *}$ & 0.121 & \\
\hline \multirow[b]{2}{*}{ Jiangmen } & Yangjiang & $0.325^{\star * *}$ & 0.027 & \multirow[b]{2}{*}{0.9995} \\
\hline & Qingyuan & $0.382^{* * *}$ & 0.033 & \\
\hline \multirow{2}{*}{ Zhaoqing } & Jieyang & $0.405^{\star * *}$ & 0.094 & \multirow{2}{*}{0.9954} \\
\hline & Yangjiang & $0.657^{\star * *}$ & 0.054 & \\
\hline
\end{tabular}

Note: ${ }^{* *}, * *,{ }^{*}$ respectively represent that the estimated coefficients pass the significance level test of $1 \%$, $5 \%$ and $10 \%$.

screened by $A I C C$ criterion is better, $\mathrm{R}$-square is above 0.9 . Therefore, we believe that the counterfactual situation after the implementation of the Outline can be predicted more accurately by the above optimal control group.

\section{Result}

Based on the counterfactual situation of the two basic indicators of real GDP and real per capita GDP, this paper calculates the three indicators of regional economic linkages, regional economic growth and regional economic disparities in the Pearl River Delta region and the Guangdong-Hong Kong-Macao Great Bay 
Area respectively after the implementation of the Outline. According to the calculation results, the paper analyzed whether the Outline had the effect of promoting the coordinated development of Guangdong-Hong Kong-Macao Great Bay Area.

\subsection{Effects on the Coordinated Development of the Pearl River Delta}

As mentioned above, the main target area of the implementation of the Outline is the Pearl River Delta region of Guangdong Province. Therefore, this paper first examines whether the implementation of the Outline promotes the coordinated development of the Pearl River Delta region. Figure 2 and Table 2 respectively reflect the actual situation and counterfactual situation of the Pearl River Delta region in three aspects: regional economic links, regional economic growth and regional economic disparities since the implementation of the Outline.

\subsubsection{Effects on Regional Economic Linkages}

To a great extent, the implementation of the Outline has promoted the economic links among cities in the Pearl River Delta region. As can be seen from Figure 3(1), after the implementation of the Outline, the economic links among cities in the Pearl River Delta region have been on the rise, with an average growth rate of 3.0\%. Table 3 shows that the net effect of regional economic linkages caused by the implementation of the Outline has increased year by year from 2009 to 2014 . The net effect in the first year is still negative, and then rises to 0.927 until 2014. Although the growth rate in 2015 is slightly slow, the overall effect of the implementation of the Outline on promoting economic linkages in the Pearl River Delta region is significantly positive.

As the economic links between cities depend largely on the transportation network between cities, the sustainable promotion effect of the Outline on the economic links within the region is mainly due to the vigorous promotion of the construction of transportation infrastructure. Since the implementation of the Outline, the mileage of grade roads in the Pearl River Delta region has increased from $48,203 \mathrm{~km}$ at the end of 2008 to $59,928 \mathrm{~km}$ by 2015 , with an average annual growth rate of about $3.2 \%$. In terms of rail transit, by the end of 2015, in addition to the three high-speed sections of Wuhan-Guangzhou high-speed railway, Guangzhou-Shenzhen high-speed railway, Guangzhou-Hong Kong high-speed railway and Huishen section of Xiamen-Shenzhen Railway, Guangzhou-Zhuhai urban rail, Guangfozhao urban rail, Guanhui urban rail and Guangzhou-Shenzhen urban rail have been completed and opened. From the point of view of development, there are 12 inter-city rail lines under construction and planned construction in the Pearl River Delta region. Therefore, it is foreseeable that in the future, these 16 lines will form a rail transit network centered on Guangzhou, connecting all prefecture-level cities and major cities and towns in the region. At that time, the Pearl River Delta region will form a closely linked integrated transportation system, which will promote economic links and interactive development 

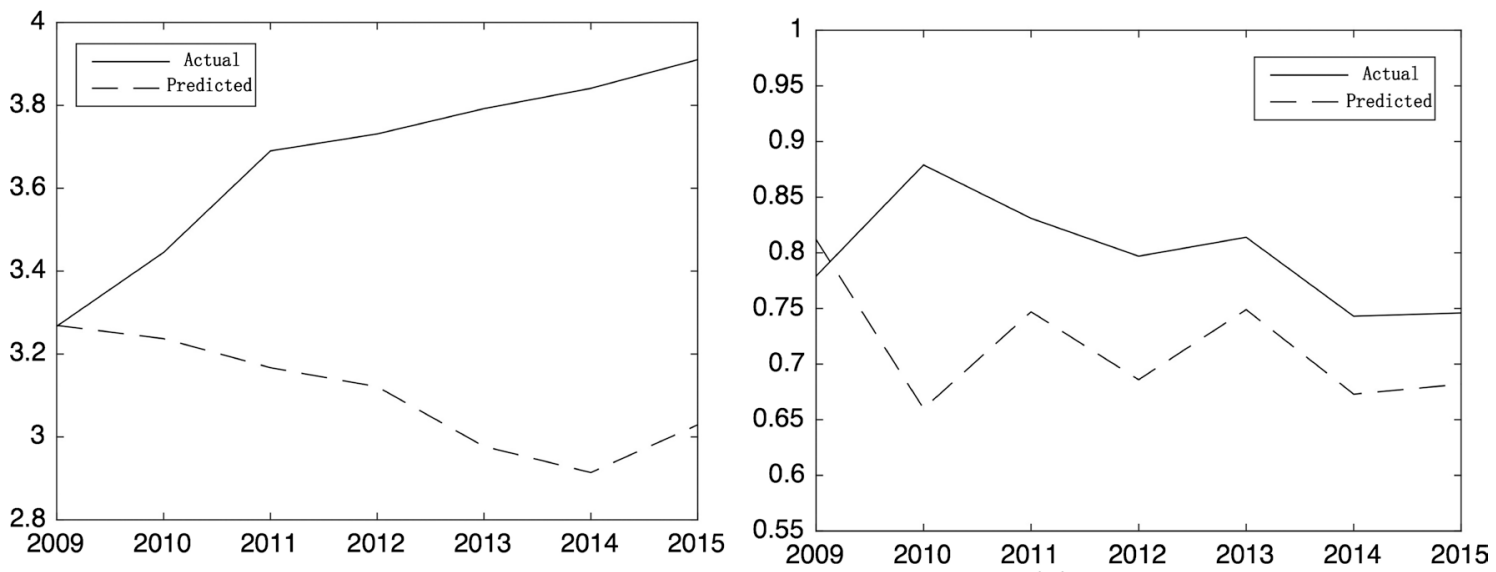

(1) Regional economic linkages

(2) Regional economic growth

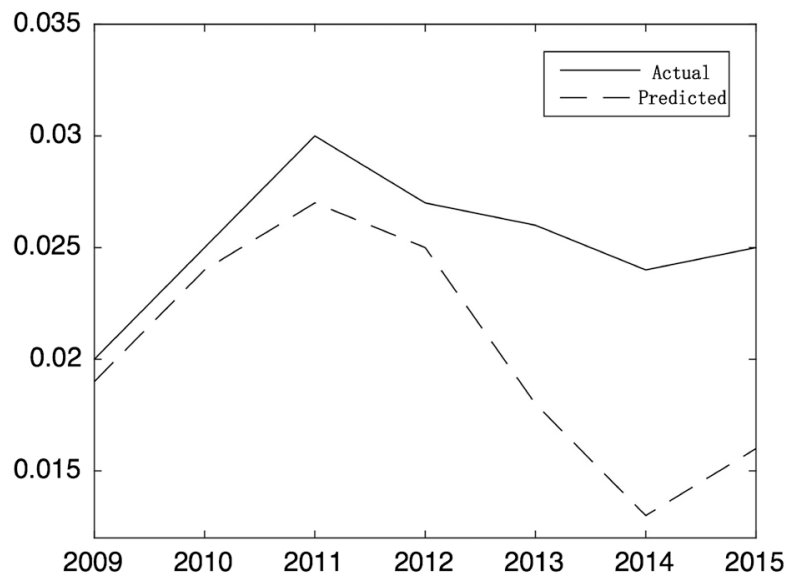

(3) Regional economic disparities

Figure 3. The actual and counterfactual situation of coordinated development in the pearl river delta region.

Table 3. The actual and counterfactual situation of coordinated development in the pearl river delta region.

\begin{tabular}{cccccccccc}
\hline Year & & 2009 & 2010 & 2011 & 2012 & 2013 & 2014 & 2015 \\
\hline & Actual & 3.267 & 3.445 & 3.69 & 3.731 & 3.792 & 3.841 & 3.91 \\
Economic linkages (D) & Predicted & 3.269 & 3.237 & 3.167 & 3.121 & 2.977 & 2.914 & 3.029 \\
& Treatment & -0.001 & 0.208 & 0.523 & 0.61 & 0.815 & 0.927 & 0.881 \\
& Actual & 0.779 & 0.879 & 0.831 & 0.797 & 0.814 & 0.743 & 0.746 \\
Economic Growth (CV) & Predicted & 0.812 & 0.66 & 0.747 & 0.686 & 0.749 & 0.673 & 0.682 \\
& Treatment & -0.032 & 0.219 & 0.084 & 0.111 & 0.065 & 0.069 & 0.064 \\
& Actual & 0.02 & 0.025 & 0.03 & 0.027 & 0.026 & 0.024 & 0.025 \\
Economic disparities (T) & Predicted & 0.019 & 0.024 & 0.027 & 0.025 & 0.018 & 0.013 & 0.016
\end{tabular}

Note: Regional economic linkages and regional economic growth are positive indicators, while regional economic disparities are negative indicators. According to $\dot{x}_{i}=\max \left\{x_{i}\right\}-x_{j}$ [19], the inverse index is processed forward. In order to avoid concealing the index information of a certain year, according to the range of index values, for regional economic growth CV, this paper takes max $\left\{x_{i}\right\}$ as 1 , for regional economic difference $\mathrm{T}, \max \left\{x_{i}\right\}$ as 0.1 . 
between cities to a greater extent.

\subsubsection{Effects on Regional Economic Growth}

From the net effects of regional economic growth in Figure 3(2) and column 7 of Table 3, it can be seen that, on the whole, the implementation of the Outline has a significant role in promoting economic growth in the Pearl River Delta region. It is worth noting that in the first year of the implementation of the Outline in 2009, the net effect of actual and counterfactual is still negative. After that, although the actual development trend of regional economic growth shows fluctuating characteristics, the actual growth of regional economy has been higher than the counterfactual situation without the implementation of the Outline since 2010, and the net effect continues to be positive, which shows that the implementation of the Outline is effective. It promotes the sustainable economic development of all regions in the Pearl River Delta region, and narrows the regional disparities in economic growth. This is an important manifestation of regional coordinated development.

The Outline puts forward the structural adjustment and upgrading requirements for the Pearl River Delta region aiming at establishing a modern industrial system, namely, giving priority to the development of modern service industries, accelerating the development of advanced manufacturing industries, vigorously developing high-tech industries, transforming and upgrading traditional superior industries, actively discovering the present agriculture and enhancing the overall competitiveness of enterprises. At the same time, it also emphasizes the integration of innovation into development. Therefore, in the process of structural adjustment and upgrading, because of the different time and degree of structural adjustment among the cities in the Pearl River Delta region, the economic growth rate of some cities slowed down, while that of other cities accelerated, so a good state of sustained economic development and narrowing the difference of growth rate appeared.

\subsubsection{Effects on Regional Economic Disparities}

Generally speaking, the implementation of the Outline has played a positive role in narrowing the economic disparities in the Pearl River Delta region. From the column 10 of Table 3, we can see that the net effect value of regional economic disparity is positive, and it increases continuously from 2009 to 2014, which shows that the implementation of the Outline has a positive impact on the reduction of regional economic disparity in the Pearl River Delta. Although the net effect decreased in 2015, it was still no less than 0.09 . Therefore, it can be judged that the implementation of the Outline has played a more significant positive role in reducing the economic disparities in the Pearl River Delta region as a whole.

\subsection{Effects on the Coordinated Development of the Great Bay Area}

Figure 3 and Figure 4 are the results of the analysis after adding Hong Kong 


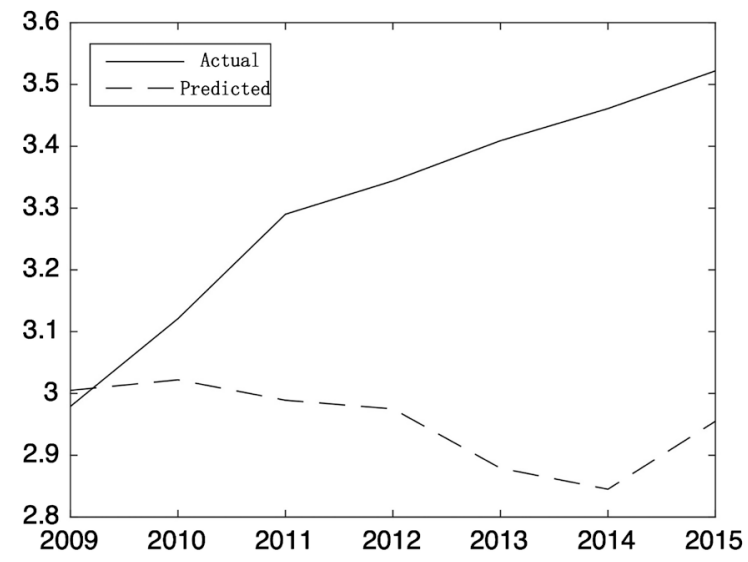

(1) Regional economic linkages

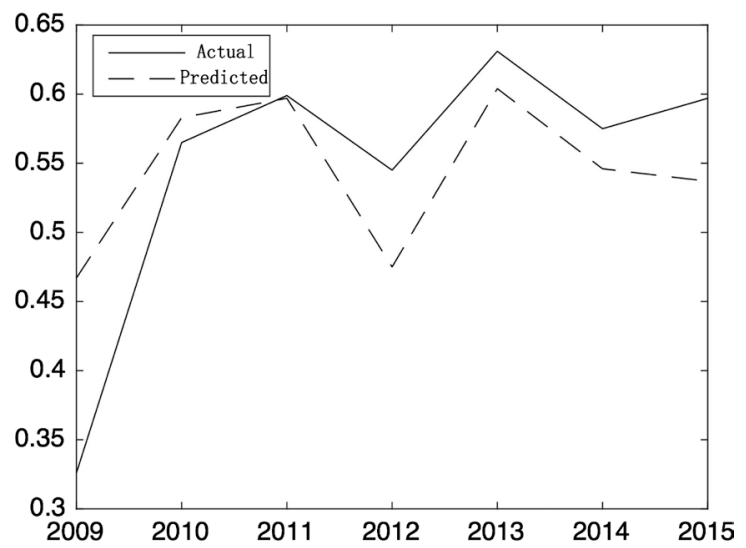

(2) Regional economic growth

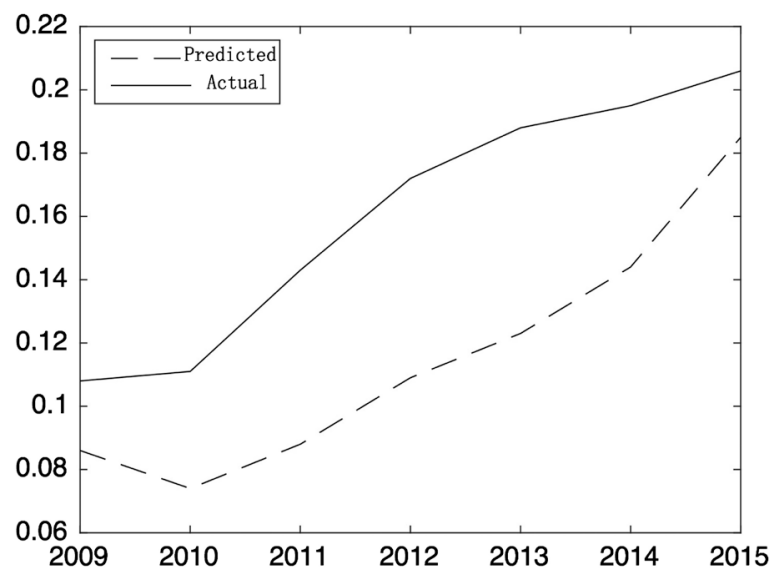

(3) Regional economic disparities

Figure 4. The actual and counterfactual situation of coordinated development in the Guangdong-Hong Kong-Macao great bay area.

and Macao to the model. Therefore, this result reflects the impact of the implementation of the Outline on the coordinated development of Guangdong-Hong Kong-Macao Great Bay Area. Next, we will analyze the impact of the implementation of the Outline on the coordinated development of the Great Bay Area from three aspects: regional economic links, regional economic growth and regional economic disparities.

\subsubsection{Effects on Regional Economic Linkages}

From Figure 4(1) and Table 4, we can see that the overall effect of the implementation of the Outline shows that the average growth rate of regional economic linkages in Guangdong-Hong Kong-Macao Great Bay Area is 2.8\% and the average degree of linkages increases by 0.351 between 2009 year and 2015 year. This shows that the economic linkages between Guangdong, Hong Kong and Macao have a sustained promotion effect compared with the counterfactual situation without the implementation of the Outline. After the opening of the Zhuhai-Macao Bridge and the future operation of the Guangzhou-Shenzhen-Hong Kong Railway in Hong Kong, the connection between Hong Kong and Macao 
Table 4. The actual and counterfactual situation of coordinated development in the Guangdong-Hong Kong-Macao great bay area.

\begin{tabular}{|c|c|c|c|c|c|c|c|c|}
\hline \multicolumn{2}{|c|}{ Year } & 2009 & 2010 & 2011 & 2012 & 2013 & 2014 & 2015 \\
\hline \multirow{3}{*}{$\begin{array}{c}\text { Economic } \\
\text { linkages (D) }\end{array}$} & Actual & 2.979 & 3.121 & 3.29 & 3.344 & 3.409 & 3.461 & 3.522 \\
\hline & Predicted & 3.005 & 3.022 & 2.989 & 2.975 & 2.879 & 2.845 & 2.955 \\
\hline & Treatment & -0.026 & 0.099 & 0.301 & 0.369 & 0.531 & 0.616 & 0.566 \\
\hline \multirow{3}{*}{$\begin{array}{c}\text { Economic } \\
\text { Growth }(\mathrm{CV})\end{array}$} & Actual & 0.326 & 0.565 & 0.599 & 0.545 & 0.631 & 0.575 & 0.597 \\
\hline & Predicted & 0.467 & 0.583 & 0.597 & 0.475 & 0.604 & 0.546 & 0.537 \\
\hline & Treatment & -0.14 & -0.082 & 0.002 & 0.07 & 0.026 & 0.029 & 0.06 \\
\hline \multirow{3}{*}{$\begin{array}{c}\text { Economic } \\
\text { disparities }(\mathrm{T})\end{array}$} & Actual & 0.086 & 0.074 & 0.088 & 0.109 & 0.123 & 0.144 & 0.185 \\
\hline & Predicted & 0.108 & 0.111 & 0.143 & 0.172 & 0.188 & 0.195 & 0.206 \\
\hline & Treatment & -0.021 & -0.037 & -0.055 & -0.063 & -0.065 & -0.051 & -0.022 \\
\hline
\end{tabular}

Note: Regional economic linkages and regional economic growth are positive indicators, while regional economic disparities are negative indicators. According to $\dot{x}_{i}=\max \left\{x_{i}\right\}-x_{j}$, the inverse index is processed forward. In order to avoid concealing the index information of a certain year, according to the range of index values, for regional economic growth $\mathrm{CV}$, this paper takes $\max \left\{x_{i}\right\}$ as 1 , for regional economic difference $\mathrm{T}, \max \left\{x_{i}\right\}$ as 0.1 .

and the cities in the Pearl River Delta will be greatly enhanced. However, it should be pointed out that the impact of the Outline on the economic linkages in the Great Bay Area is less than that in the Pearl River Delta. In these seven years, the average economic linkages in the Pearl River Delta are 3.102, while that in the Great Bay Area is 2.953. Under the implementation of the Outline, the average economic linkage degree of the Pearl River Delta is 3.668, while that of the Great Bay Area is 3.304. This is in line with the reality. Because of its geographical proximity, Hong Kong, Macao and most cities in the Pearl River Delta are far less closely connected with Shenzhen and Zhuhai, thus lowering the overall regional economic linkages. In addition, the main body of the Outline is the Pearl River Delta in policy design and implementation. As far as transport links are concerned, the high-speed railway between Hong Kong and Shenzhen didn't operated until 2018, and the Hong Kong-Zhuhai-Macao Bridge connecting Hong Kong, Macao and Zhuhai haven't opened yet. So far, Macao has no rail transit links with the Mainland. All these restrict the connection between Hong Kong, Macao and the Pearl River Delta.

\subsubsection{Effects on Regional Economic Growth}

From Figure 3(2), on the whole, the implementation of the Outline has played a positive role in promoting the economic growth of the cities in the GuangdongHong Kong-Macao Great Bay Area and narrowing the differences in the economic growth rate. As mentioned in the analysis above, under the influence of the Outline, 9 in 11 cities in the Great Bay Area have been restructuring and upgrading, and have maintained a good growth trend as a whole. The economic growth of Hong Kong and Macao relies heavily on the international economy. In 
recent years, the sustained downturn of international economic growth has had a greater impact on its economic growth. In addition, Hong Kong and the Pearl River Delta have declined in the "front store and back factory" model, Macao is limited to "gambling island", and the economic cooperation model of Guangdong, Hong Kong and Macao is also in the transition stage, which has affected the economic growth of Hong Kong and Macao to a certain extent. Therefore, it can be expected and understood that the actual curve of regional overall economic growth has slowed down in recent years. It is also noteworthy that, compared with the counterfactual situation, we can see that, except for the first two years of the implementation of the Outline, from 2011, the net effect value continued to be positive, with an average net effect of 0.0374 . This shows that under the adverse external economic environment, the actual economic development and counterfactual development of the cities in the Great Bay Area have slowed down, But the Outline has promoted the economic growth of various cities in varying degrees and is conducive to narrowing the differences in their growth rates.

\subsubsection{Effects on Regional Economic Disparities}

From the comparison of Figure 3(3) and Figure 4(3), columns 8 - 10 of Table 3 and Table 4, it can be seen that after joining Hong Kong and Macao for analysis, the regional economic disparity coefficient of the Great Bay Area has decreased. Specifically, under counter-factual circumstances, the average value of the Pearl River Delta region is 0.02, and that of the Great Bay Area is 0.16. Under the implementation of the Outline, the Pearl River Delta area is 0.025, and t the Great Bay Area is 0.115 . This is also in line with the reality, because most cities in Hong Kong, Macao and the Pearl River Delta still have large differences in the level of economic growth. In addition, it is worth noting that although the net effects of the Great Bay Area are negative, its growth rate of economic disparity indicators under the counter-factual circumstances has slowed down, while under the implementation of the Outline, the growth rate has an obvious upward trend, which is only $17.4 \%$ in 2014 and rises to $28.4 \%$ in 2015 . This shows that although the Outline promotes the overall economic development of Guangdong- Hong Kong-Macao Great Bay Area, and narrows the regional economic disparities, its role is still limited.

\section{Conclusions}

This paper uses HCW model to analyze the impact of the Outline on the coordinated development of the Pearl River Delta and the Great Bay Area respectively from three aspects: regional economic linkages, regional economic growth and regional economic disparities. The main conclusions are as follows: First, the implementation of the Outline has significantly enhanced the economic linkages within the Great Bay Area and the Pearl River Delta. However, comparatively speaking, the impact on the former is less than that on the latter. Secondly, on the whole, the Outline has played a positive role in the economic growth of 
both the Great Bay Area and the Pearl River Delta, as well as in the reduction of economic growth among cities. Thirdly, the implementation of the Outline has no obvious effect on the narrowing of economic disparities in Guangdong-Hong Kong-Macao Great Bay Area, but it has played a positive role in promoting the narrowing of economic disparities in the Pearl River Delta.

The above three main conclusions show that, on the whole, the implementation of the Outline has a positive impact on the coordinated development of the Great Bay Area and the Pearl River Delta. In terms of strengthening regional economic linkages, the significant impact of the Outline deserves special attention. On the one hand, the strengthening of regional economic ties is an important prerequisite for achieving regional coordinated development. On the other hand, according to the analysis of this paper, the Outline strengthens the economic links within the Guangdong-Hong Kong-Macao Great Bay Area and the Pearl River Delta by strengthening the construction of transportation network. This experience deserves to be applied in the construction of the Guangdong-Hong Kong-Macao Great Bay Area. Especially, in the future construction of Great Bay Area, how to effectively play the role of Hong Kong-Zhuhai-Macao Bridge and Shenzhen-Hong Kong High-speed Rail, connect Guangzhou-Zhuhai Urban Rail Transit with Macao Rail Transit, speed up the construction of $\mathrm{Hu}$ men Second Bridge, Shenzhen-Zhongshan Bridge, and plan and construct Lingdingyang Railway Bridge, all need to make scientific arrangements, so as to better play these projects to enhance internal economic ties of Great Bay Area.

In promoting regional economic growth, the implementation of the Outline has also played a positive role in the economic growth and the narrowing of Economic Growth Disparities among cities. It is noteworthy that the Outline has focused on promoting the structural adjustment and upgrading of the Pearl River Delta region. A new structure, with innovation as the driving force and advanced manufacturing and modern service industries as the main body, is being formed. Therefore, its role in the economic growth of the Pearl River Delta region and the reduction of economic growth among cities is more obvious. It can be predicted that the new industrial structure formed under the guidance of the Outline will surely lead to a new round of rapid economic growth in the Pearl River Delta region. The inspiration from this is that in the construction of the Great Bay Area, we still need to continue structural adjustment. For Hongkong and Macao, we should pay special attention to the adjustment of the structure to adapt to the great changes in the development environment brought about by the new technological revolution and the fourth industrial revolution and the construction of "one belt and one road".

In terms of reducing regional economic disparities, the Outline has no obvious effect on the narrowing of economic disparities in the Guangdong-Hong Kong-Macao Great Bay Area, but has a positive effect in the Pearl River Delta region. However, it is worth noting that its role in narrowing the economic disparities in the Great Bay Area is increasing year by year. Based on the above 
analysis, we believe that in the construction of the Great Bay Area, we should first strengthen the construction of the rapid transportation network and bring Hong Kong and Macao into the Pearl River Delta to strengthen their economic ties; second, we should overcome the obstacles caused by the "one country, two systems" to the connection between Hong Kong and Macao and the Pearl River Delta, and promote interaction and integration between them. Third, the Pearl River Delta region should continue to intensify its transformation and upgrading efforts to achieve more open and high-quality economic development, and gradually narrow the economic gap between Hong Kong and Macao at the per capita level.

In addition, the analysis of the Outline on promoting the coordinated development of Guangdong-Hong Kong-Macao Great Bay Area and the Pearl River Delta provides an empirical reference for the implementation of the Outline and the promotion of the coordinated development of the Great Bay Area, and also provides a positive case support for the theoretical construction of regional planning to promote the coordinated development of the region.

\section{Conflicts of Interest}

The author declares no conflicts of interest regarding the publication of this paper.

\section{References}

[1] Xie, D. and Jiang, H. (2011) Regional Planning and Regional Governance of the Pearl River Delta Urban Agglomeration Area: Based on the Outline of the Pearl River Delta Regional Reform and Development Planning. Planner, 27, 16-19+24.

[2] Yao, H. and Xu, X. (2009) Continue to Promote Reform, Opening up and Innovation, and Create a New Situation for the Development of the Pearl River Delta-Interpretation of the Outline of the Pearl River Delta Regional Reform and Development Plan (2008-2020). Special Economic Zone, 23-24.

[3] Ma, L. and Xu, Q. (2014) Summary of the Reform and Development Plan of the Pearl River Delta (2008-2020). Shang, 58-59.

[4] Peng, X. (2015) Research on the Process of Industrial Integration in the Pearl River Delta since the Implementation of the Outline. Guangdong Economy, 38-43.

[5] Guo, F. and Song, Y. (2012) Effectiveness Analysis of Local Government Policy Innovation: Taking the Implementation of the Pearl River Delta Planning Outline as an Example. Journal of Fujian Commercial College, 27-31.

[6] Rubin, D.B. (1974) Estimating Causal Effects of Treatments in Randomized and Nonrandomized Studies. Journal of Educational Psychology, 66, 688-701. https://doi.org/10.1037/h0037350

[7] Hahn, T. and Vander, K. (2001) Identification and Estimation of Treatment Effects with a Regression Discontinuity Design. Econometrica, 69, 201-209. https://doi.org/10.1111/1468-0262.00183

[8] Card, D. and Krueger, A.B. (1994) Minimum Wages and Employment: A Case Study of the Fast-Food Industry in New Jersey and Pennsylvania. American Economic Review, 84, 772-793.

[9] Zheng, X., Wang, H. and Zhao, Y. (2011) “Provincial Governance of Counties" Can 
Promote Economic Growth?-Double Difference Method. Managing the World, $34-44+65$.

[10] Heckman, J.J., Ichimura, H. and Todd, P.E. (1997) Matching as an Econometric Evaluation Estimator: Evidence from Evaluating a Job Training Programmed. The Review of Economic Studies, 64, 605-654. https://doi.org/10.2307/2971733

[11] Hsiao, C., Ching, H.S. and Wan, S.K. (2012) A Panel Data Approach for Program Evaluation: Measuring the Benefits of Political and Economic Integration of Hong Kong with Mainland China. Journal of Applied Econometrics, 27, 705-740. https://doi.org/10.1002/jae.1230

[12] Ching, S., Cheng, H. and Wan, S.K. (2012) Impact of CEPA on the Labor Market of Hong Kong. China Economic Review, 23, 975-981. https://doi.org/10.1016/j.chieco.2012.04.017

[13] Ke, X., Chen, H., Hong, Y., et al. (2017) Do China's High-Speed-Rail Projects Promote Local Economy?-New Evidence from a Panel Data Approach. China Economic Review, 44, 203-226. https://doi.org/10.1016/j.chieco.2017.02.008

[14] Cheng, H. and Shui, K.W. (2014) Is There an Optimal Forecast Combination? Journal of Econometrics, 178, 294-309.

https://doi.org/10.1016/j.jeconom.2013.11.003

[15] Peng, R. (2007) Study on the Connotation, Mechanism and Evaluation of Coordinated Development of Regional Economy. Henan University, Zhengzhou.

[16] Su, F. (2013) Evaluation of Coordinated Development of Regional Economy-Taking Lanbai Area of Gansu Province as an Example. Productivity Research, 27, 110-133.

[17] Yin, A. and Chen, J. (2015) Evaluation of Coordinated Development of Regional Economy in Shandong Province. Journal of Gansu Science, 27, 129-133.

[18] Qin, C., Zhang, H. and Mao, C. (2011) Coordinated Development of Regional Economy: Concept Discrimination, Criteria for Judgment and Evaluation Methods. Economic System Reform, 34-38.

[19] Ye, Z. (2003) On the Selection of the Methods of Index Forward and Dimensionless in Multi-Index Comprehensive Evaluation. Zhejiang Statistics, 25-26. 